Research Article

\title{
Elastoplastic Model and Three-Dimensional Method for Unsaturated Soils
}

\author{
Jinjin Fang $\mathbb{D}^{1}$ and Yixin Feng $\mathbb{D}^{2}$ \\ ${ }^{1}$ School of Civil Engineering, Henan Polytechnic University, Jiaozuo 454000, China \\ ${ }^{2}$ Capital Construction Department, Henan Polytechnic University, Jiaozuo 454000, China
}

Correspondence should be addressed to Yixin Feng; 327256272@qq.com

Received 13 August 2019; Revised 26 January 2020; Accepted 21 February 2020; Published 13 May 2020

Academic Editor: M. I. Herreros

Copyright (c) 2020 Jinjin Fang and Yixin Feng. This is an open access article distributed under the Creative Commons Attribution License, which permits unrestricted use, distribution, and reproduction in any medium, provided the original work is properly cited.

\begin{abstract}
This paper proposed a new elastoplastic constitutive model to predict the deformation and strength behaviour of unsaturated soils. Applying the modified Cambridge model as a generalization, the degree of saturation is introduced into the elastoplastic model of unsaturated soil. Under the condition of ensuring that the model parameters are unchanged, the model is transformed into three dimensions based on the SMP criterion transformation stress method. Enhanced modified van Genuchten model under true triaxial conditions is also proposed in this paper to describe hydromechanical behaviours of unsaturated soils. The proposed constitutive model can capture the observed mechanical and hydraulic behaviours. Then, the model is validated via equal $p$ and equal $b$ value true triaxial tests, and the results show that a reasonable agreement can be obtained.
\end{abstract}

\section{Introduction}

The study of the stress-strain constitutive relation of unsaturated soils has lasted for more than 50 years. The first variable used for unsaturated soil constitutive model is the Bishop effective stress [1]; the formulation of Bishop's effective stress $\left(\sigma_{\mathrm{ij}}^{\prime}\right)$ can be written as follows:

$$
\sigma_{\mathrm{ij}}^{\prime}=\sigma_{\mathrm{ij}}-u_{a}+\chi\left(u_{\mathrm{a}}-u_{\mathrm{w}}\right) \delta_{\mathrm{ij}}
$$

where $\sigma_{\mathrm{ij}}$ is the total stress, $u_{\mathrm{a}}$ and $u_{\mathrm{w}}$ are the pore air and pore water pressure, $\chi$ is the effective stress parameter, and $\delta_{\mathrm{ij}}$ is the Kronecker delta. Coleman [2] suggested the incremental stress-strain relations to relate changes in $s$ $\left(=u_{\mathrm{a}}-u_{\mathrm{w}}\right)$ and $\left(\sigma_{\mathrm{ij}}-u_{\mathrm{a}} \delta_{\mathrm{ij}}\right)$ to the strain response of the soil. Blight [3] studied the constitutive equation of volumetric deformation based on the formulation of Bishop's effective stress. The formulation can be expressed as follows:

$$
-\Delta\left(\frac{d v}{v}\right)=c \Delta\left[\left(\sigma-u_{\mathrm{a}}\right)+\chi\left(u_{\mathrm{a}}-u_{\mathrm{w}}\right)\right],
$$

where $v$ is the specific volume, $\left(\sigma-u_{\mathrm{a}}\right)$ is the net stress, $\left(u_{\mathrm{a}}-u_{\mathrm{w}}\right)$ is the suction, and $\chi$ is the effective stress parameter.
Jennings and Burland [4] pointed out that single Bishop's effective stress cannot be used to explain and predict the mechanical behaviour of unsaturated soils (the loading collapse behaviour particularly). Fredlund et al. [5] suggested that the behaviour of an unsaturated soil can be written in terms of two independent stress state variables, i.e., net stress and suction. Based on two independent stress state variables, Fredlund et al. [6] established the constitutive equation of the soil skeleton in the following form:

$$
\varepsilon=c_{\mathrm{t}} d\left(\sigma-u_{\mathrm{a}}\right)+c_{\mathrm{a}} d\left(u_{\mathrm{a}}-u_{\mathrm{w}}\right),
$$

where $\varepsilon=\varepsilon_{\mathrm{x}}+\varepsilon_{\mathrm{y}}+\varepsilon_{\mathrm{z}}, c_{\mathrm{t}}$ and $c_{\mathrm{a}}$ represent the compression indices of the soil associated with net stress and suction, respectively.

In the late 1980s, Alonso et al. [7, 8] first proposed an elastoplastic constitutive model (i.e., Barcelona basic model) of unsaturated soils based on the concept of critical state of saturated soils. The model takes net stress and suction as stress state variables, which cannot only describe the mechanical properties of nonexpansive unsaturated soils, but also predict the characteristics of collapse deformation and yield stress increasing with suction. Loading collapse yield 
curve (LC) is the most important part of BBM model; it is originally the expression of isotropic yield stress and suction derived when plastic bulk strain of unsaturated soils reached the same under different suction conditions; however, it also reflected the yield stress of unsaturated soil increase with an increase in suction. Later, on the basis of adhering to the advantages of Alonso model, a large number of models [9-15] were proposed to explain the mechanical behaviour of unsaturated soils. Kohgo et al. [9] formulated effective stress equations using shear strength of soil on the wet side of the critical state line and proposed an elastoplastic model taking into account two suction effects, i.e., the critical suction and the effective suction. The model is formulated using the newly defined effective stress for unsaturated soils. Wheeler et al. [10] used a series of controlled suction triaxial tests on samples of compacted Speswhite kaolin in the development of an elastoplastic critical state framework for unsaturated soil; the framework is defined in terms of four state variables: mean net stress, deviator stress, suction, and specific volume. Cui et al. [11] performed an experimental programme in an osmotically controlled suction triaxial apparatus within the framework of an extended elastoplastic constitutive model for unsaturated soils (loading collapse (LC) model) and found a hyperbolic plastic potential, similar to that of sand. Then, volume change prediction appeared satisfactory, showing the validity of the hyperbolic plastic potential. Konstantinos et al. [12] implemented an exponential expression for partially saturated isotropic compression lines in an existing elastoplastic framework for saturated and partially saturated soils. As a result, the presented constitutive relationship was more flexible in its ability of modeling the collapse behaviour of partially saturated soils over a larger range of suctions and stresses. Shamsabadi [13] investigated that partially water saturated condition in soils may change the cone penetration resistance comparing with that of dry or saturated conditions by using numerical finite element modeling and experimental centrifuge testing. Jarast et al. [14] modelled numerically on cone penetration test in unsaturated sand using Finite Element Method. Simple elastic perfectly plastic Mohr-Coulomb constitutive model is modified with an apparent cohesion to incorporate the effect of suction on cone resistance. The Arbitrary Lagrangian-Eulerian (ALE) remeshing algorithm is also implemented to avoid mesh distortion problem due to the large deformation in the soil around the cone tip. Ghayoomi et al. [15] described the modification of a suction-controlled cyclic triaxial apparatus to investigate the strain-dependent shear modulus of unsaturated soils.

However, the above models [9-12] only consider the suction and do not consider the influence of the degree of saturation on the stress-strain and strength of unsaturated soils. They can only predict the mechanical properties of unsaturated soils but cannot predict the degree of saturation of unsaturated soil. The degree of saturation is constantly changing in the process of suction change and soil deformation, and soil deformation also has a great impact on soilwater retention characteristics. At the same time, when the suction is the same, the deformation and strength characteristics of unsaturated soils will change with the different degrees of saturation [16-18]. Hence, the degree of saturation is also an important factor affecting the strength and deformation of unsaturated soils. In response to the above problems, a large number of scholars [16, 19-23] used the elastoplastic model and the soil-water characteristic curve to describe the mechanical properties and water retention behaviour of unsaturated soils, respectively. However, the mechanical properties and water retention behaviour of soil are considered separately, leading to uncorrelated relationship of these two properties. As a result, neither the influence of deformation on the soil-water characteristics of unsaturated soils, nor the influence of the degree of saturation on the mechanical properties of unsaturated soils can be studied. In fact, the water retention behaviour (such as the degree of saturation) and mechanical properties (such as deformation and strength) of unsaturated soils will change under the action of external stresses (including net stress and suction) [16-18]. Therefore, the above-mentioned unsaturated soil elastoplastic constitutive models [7-12] or soil-water characteristic curves $[16,19,20,23]$ cannot uniformly describe the mechanical properties and water retention behaviour of unsaturated soils.

In addition, it is necessary to realize three-dimensional elastic-plastic constitutive model to obtain the deformation and strength characteristics of unsaturated soils under threedimensional stress state. At present, the commonly used model three-dimensional methods are as follows [24-30]: (1) a three-dimensional method of the generalized Mises criterion is used for the yield and strength criteria; (2) a threedimensional method is using the generalized Mises criterion as the yield criterion and the Mohr-Coulomb criterion as the strength criterion; (3) a three-dimensional method directly introduces strength criterion into the model; (4) a method of shape function $g(\theta)$ proposed by Zienkiewicz-Pande $[28,32,33]$ is a function of the strength curve on the $\pi$ plane varying with the Lode angle. However, the methods (1) and (2) cannot describe the change of soil strength with the Lode angle; the method (4) cannot reasonably reflect the influence of stress level (i.e., friction angle) on deformation strength, and the yield surface appears to be severe discontinuity under $K_{0}$ conditions [28, 32, 33]. Later, Matsuoka et al. [31] and Yao et al. [25-27] proposed a three-dimensional method of transforming stress within taking into account the effects of stress Lord angle and friction angle. The method has the following characteristics [25-27, 31]: (1) the model form is the same as the original model; (2) the model parameters remain unchanged; (3) the model is the same as the original model under triaxial compression; (4) the model achieves continuity from shear yielding to shear failure on the yield surface of $\pi$ plane, and the failure surface obeys the strength criterion employed.

Based on the above understanding, this paper applies the modified Cambridge model as a generalization, introduces the degree of saturation into the elastoplastic model of unsaturated soils, and realizes the three-dimensional modeling of the unsaturated soil elastoplastic constitutive model. At the same time, comparing the experimental data 
with the predictions of the model, the capability of established model is verified that the model can well predict the stress-strain relationship and the variation of degree of saturation under different intermediate principal stress parameter $b$ values.

\section{Elastoplastic Constitutive Model}

2.1. Stress State Variables. The elastoplastic model of unsaturated soils needs to establish an appropriate mathematical model between the selected stress state variables and the strain state variables of unsaturated soils, so that the elastic strain variations and plastic strain variations can be calculated correspondingly according to the change of stress. At present, in the study of elastoplastic models of unsaturated soils, the Alonso model is a widely representative model. However, one shortcoming of Alonso model is that it just investigates the influence of stress suction on the deformation of soil. As a result, the influence of the change of degree of saturation on soil properties cannot be reflected in this model. Moreover, the same suction will have different degrees of saturation due to hydraulic hysteresis, which will affect the stiffness, deformation, and strength of the soils [34-38]. Therefore, combining hydraulic hysteresis and mechanical properties of unsaturated soils is not only a hot spot of current research, but also a difficult point of research [36-38]. This paper uses the average soil skeleton stress and suction as the stress state variable and uses the soil skeleton strain and the degree of saturation as the strain state variable to investigate the influence of suction and degree of saturation on the mechanical properties of unsaturated soils. Bolzon et al. [16] defined the effective average stress (average soil skeleton stress); the equation can be written as follows:

$$
p^{\prime}=p+S_{\mathrm{r}} s
$$

where $p$ is the net average stress, $S_{\mathrm{r}}$ is the degree of saturation, and $s$ is suction. Compared with the Bishop effective stress equation [1], the effective stress parameter $\chi$ is replaced by the degree of saturation $S_{\mathrm{r}}$, and recently using the degree of saturation $S_{\mathrm{r}}$ as the effective stress parameter it is getting more and more popular [16, 36, 38, 39]. According to the equation of the mechanical work input to an unsaturated soil proposed by Houlsby [40], it is concluded that the average soil skeleton stress and suction can be conjugated with the soil skeleton strain and degree of saturation. Therefore, it is appropriate to take the soil skeleton strain and the degree of saturation as the strain state variables and the average soil skeleton stress and suction as stress state variables.

\subsection{Constitutive Model under Isotropic Stress Conditions.} The most critical issue in establishing a constitutive relationship under isotropic stress conditions is to determine the shape of the load collapse yield line (i.e., the LC yield line). Referring to the method of establishing LC yield line similar to BBM, the average skeleton stress is adopted in this paper. The equation can be written as follows [8]:

$$
\left(\frac{p_{0}^{\prime}}{p_{c}^{\prime}}\right)=\left(\frac{p_{0}^{*}}{p_{c}^{\prime}}\right)^{(\lambda(0)-\kappa / \lambda(s)-\kappa)}
$$

where $p_{0}^{\prime}$ and $p_{0}^{*}$ are the yield stresses of unsaturated soils and saturated soils, respectively. $p_{c}^{\prime}$ is isotropic stress that does not make wetting deformation when suction is reduced; $\lambda(0)$ and $\lambda(s)$ are the slopes of the normal compression curves of saturated soils and unsaturated soils on the $e-\ln p^{\prime}$ plane, respectively. $\kappa$ is the expansion index of unsaturated soils.

When the stress point is on the LC yield line, the plastic volumetric strain increment is expressed as follows:

$$
\mathrm{d} \varepsilon_{\mathrm{v}}^{\mathrm{p}}=\frac{[\lambda(0)-\kappa]}{1+e} \frac{\mathrm{d} p_{0}^{*}}{p_{0}^{*}}
$$

When the stress point is within the LC yield line, the elastic volumetric strain increment is expressed as follows:

$$
\mathrm{d} \varepsilon_{\mathrm{v}}^{\mathrm{e}}=\frac{\kappa}{1+e} \frac{\mathrm{d} p^{\prime}}{p^{\prime}} .
$$

The expression of $\lambda(s)$ is given as follows [21, 22, 41, 42]:

$$
\lambda(s)=\lambda(0)+\frac{\lambda_{\mathrm{s}} s}{p_{\mathrm{a}}+s},
$$

where $\lambda_{\mathrm{s}}$ is material parameter. Equation (5) can be converted into an incremental form as

$$
\mathrm{d} p_{0}^{\prime}=\frac{\partial p_{0}^{\prime}}{\partial p_{0}^{*}} \mathrm{~d} p_{0}^{*}+\frac{\partial p_{0}^{\prime}}{\partial s} \mathrm{~d} s
$$

where

$$
\begin{gathered}
\frac{\partial p_{0}^{\prime}}{\partial p_{0}^{*}}=\frac{\lambda(0)-\kappa}{\lambda(s)-\kappa}\left(\frac{p_{0}^{*}}{p_{\mathrm{c}}^{\prime}}\right)^{\lambda(0)-\lambda(s) / \lambda(s)-\kappa}, \\
\frac{\partial p_{0}^{\prime}}{\partial s}=\frac{\lambda_{\mathrm{s}} p_{\mathrm{a}} p_{0}^{\prime}[\lambda(0)-\kappa]}{\left(p_{\mathrm{a}}+s\right)^{2}[\lambda(s)-\kappa]^{2}} \ln \frac{p_{\mathrm{c}}^{\prime}}{p_{0}^{*}} .
\end{gathered}
$$

2.3. Modified Van Genuchten Model under True Triaxial Conditions. The soil-water characteristic curve (SWCC) of unsaturated soils is a curve describing the relationship between suction and degree of saturation (or water content). Many mathematical models are constructed and it is very complex to apply these models to the coupled model directly [43-47]. Moreover, there are many factors affecting the SWCC mathematical model, such as mineral composition, pore structure, stress history, stress state, and temperature [48-50]. The investigation of soil-water characteristic curve of unsaturated soils cannot study only the relationship between matric suction and water content, because the matric suction is related not only to the water content of soils but also to the initial dry density, initial structure, disturbance, humidification and loading history (normal dry and ultra-dry), stress state, etc. The change of the stress state not only changes the pore structure inside the soil but also causes the change of water and gas state in the pore, which eventually leads to the complex change of the matric suction 
[48-50]. In [51], the authors studied the soil-water characteristic curves of unsaturated intact loess under stress-free, true triaxial undrained isotropic compression, and shear conditions; however, the soil-water characteristic curve equations obtained under true triaxial conditions cannot be unified. The van Genuchten model is a continuous soil-water characteristic curve model. The model fits degree of saturation versus soil suction data over the entire range of soil suctions $[44,46]$; due to this reason, the van Genuchten equation is used in the analysis of this paper; for specific test schemes and data, see [51]. The van Genuchten can be described as follows:

$$
S_{\mathrm{r}}=\frac{w G_{s}}{e}=\left[1+(a s)^{n}\right]^{-m},
$$

where $S_{\mathrm{r}}$ is the degree of saturation, $w G_{\mathrm{s}}$ is water-soil volume ratio, $e$ is the void ratio, and $a, m$, and $n$ are the model parameters. Tarantino [52] presents an experimental study on water retention behaviour of two reconstituted soils. These soils were used with the aim of encompassing a wide range of soil types and soil fabrics. On the basis of the experimental data, a modification to van Genuchten's model is proposed to account for the effect of void ratio on 'main drying' and 'main wetting' behaviour. The model can properly describe water retention at medium and low degrees of saturation. The model applies to both compacted and reconstituted soils investigated in this programme and describes water retention behaviour regardless of whether the degree of saturation is changed in a mechanical or hydraulic fashion. When the SWCC is expressed by the full logarithm of $w G_{\mathrm{s}}$ and $s$, the SWCC can be normalized to a straight line at pressure and no pressure; the equation can be described as follows [52]:

$$
w G_{\mathrm{s}}=a s^{-b_{0}}
$$

where $a$ and $b_{0}$ are parameters and $a$ and $b_{0}$ are the intercept and slope of the fitted line, respectively. Combining (12) with (13), Tarantino [52] proposed a modified van Genuchten model, and the modified van Genuchten equation is obtained as

$$
S_{\mathrm{r}}=\frac{w G_{\mathrm{s}}}{e}=\left\{1+\left[\left(\frac{e}{a}\right)^{-b_{0}} s\right]^{n}\right\}^{-\left(b_{0} / n\right)},
$$

where $a, b_{0}$, and $n$ are the model parameters. Equations (12) and (14) all have three parameters, namely, $a, m$, and $n$ and $a$, $b_{0}$, and $n$. However, $a$ and $b_{0}$ can be obtained from the intercept and slope of the $\ln s-\ln \left(w G_{\mathrm{s}}\right)$ curve; $n$ only needs to be determined by fitting curve between degree of saturation and matric suction, so it is very convenient.

Figure 1 shows the full logarithmic relationship of $\mathrm{w}_{\mathrm{s}}-\mathrm{s}$ under unstressed (denoted by $\mathrm{W}$ ) and pressurized (consolidated and sheared) conditions of intact loess. As shown in Figure 1, the test points can be approximated to a straight line under unstressed and pressurized conditions, and the soil parameters can be obtained as $a=1.1943$ and $b_{0}=0.202$.

Figure 2 shows the relationship between the degree of saturation $S_{\mathrm{r}}$ and matric suction $s$. The fitting result under no stress conditions is $n=-0.2$ (see Figure 2(a)), and under

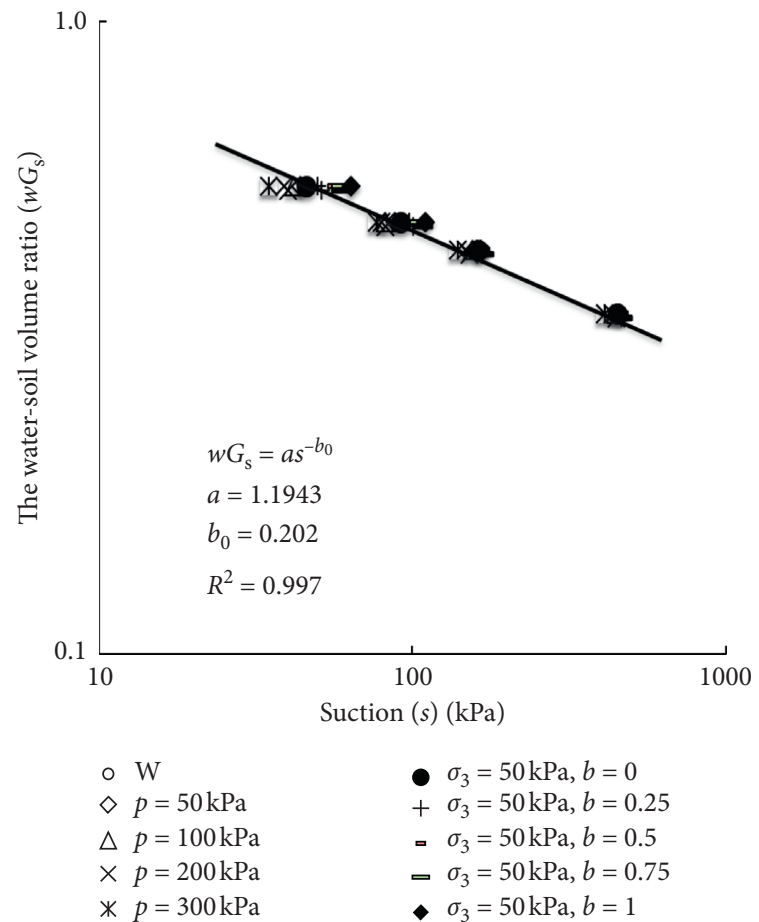

Figure 1: The relations between the water-soil volume ratio $w G_{\mathrm{s}}$ and suction $\mathrm{s}$.

isotropic net average spherical stress conditions $n=-0.252$ (see Figure 2(b)). For a given $b$ value, Figure 2(c) shows the relationship between the degree of saturation and suction at different net confining pressures $\left(\sigma_{3}=50,100,200\right.$, and $300 \mathrm{kPa}$ ); the modified Van Genuchten model can fit the test results well at a single $b$ value, but the test points under different $b$ values cannot be uniformly fitted by the modified van Genuchten model. As the $b$ value increases, the fitting curve shows a trend of moving to the upper right, indicating that the degree of saturation increases with an increase in $b$ value when the suction is constant. When the degree of saturation is constant, the suction increases with an increase in $b$ value. Hence, the modified van Genuchten model fitting curve has a good reflection in the variation of soil-water characteristic curve under true triaxial shear conditions. When $b=0,0.25,0.5,0.75$, and 1 , the fitting results are $n=-0.302,-0.322,-0.328,-0.336$, and -0.341 , respectively. Moreover, it can be seen from Figure 2 that the predicted value of the modified van Genuchten model agrees well with the measured values, and the practicability of the modified van Genuchten model for the soil-water characteristic curve of intact loess in Xi'an is verified.

Figure 3 shows the curve between the soil parameter $n$ and the intermediate principal stress parameter $b$ value. As shown in Figure 3, $n$ decreases linearly with an increase in $b$ value, and the fitting function can be expressed as

$$
n=-0.0368 b-0.3074 \text {. }
$$

Substituting (15) into (14), the modified van Genuchten model under true triaxial shear conditions can be obtained as follows: 


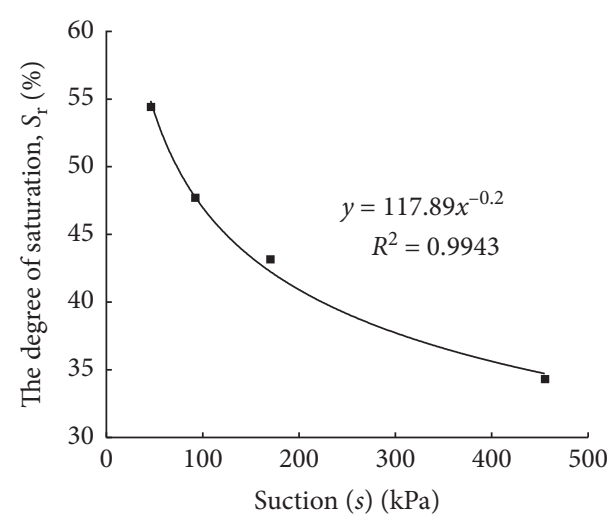

- W

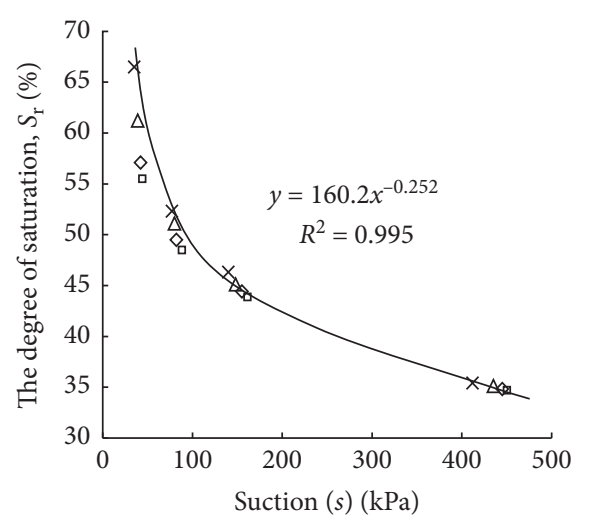

$\begin{array}{ll}\square p=50 \mathrm{kPa} & \triangle p=200 \mathrm{kPa} \\ \diamond p=100 \mathrm{kPa} & \times p=300 \mathrm{kPa}\end{array}$

(b)

(a)

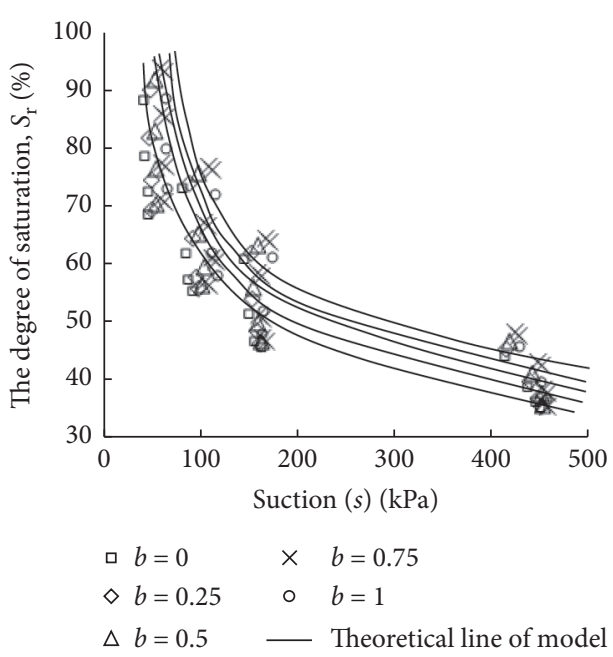

(c)

FIgURE 2: The relations between the degree of saturation and suction. (a) Under no pressure, $n=-0.2$. (b) Under isotropic spherical stress, $n=-0.252$. (c) At different net confining pressures and $b$ values.

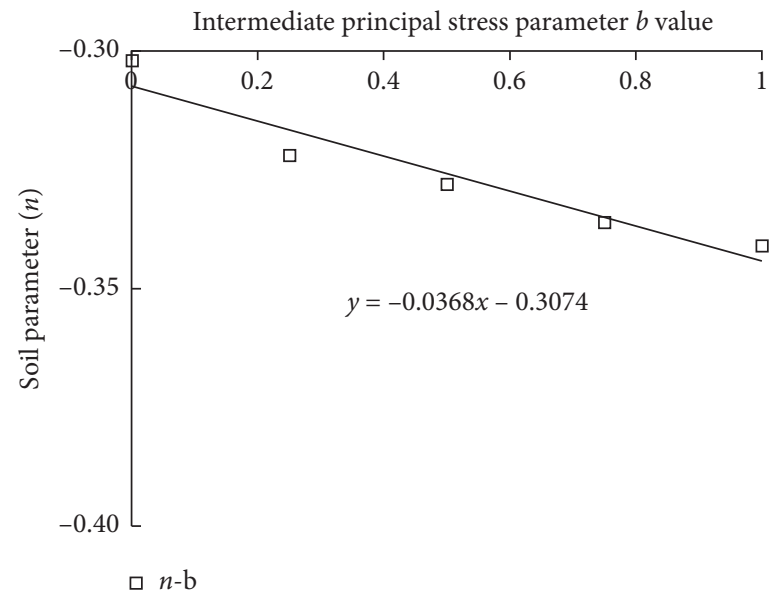

FIgURE 3: The relations between soil parameter $\mathrm{n}$ and intermediate principal stress parameter $b$ value. 
$S_{\mathrm{r}}=\frac{w G_{\mathrm{s}}}{e}=\left\{1+\left[\left(\frac{e}{a}\right)^{-0.202} s\right]^{(-0.0368 b-0.3074)}\right\}^{\left(b_{0} / 0.0368 b+0.3074\right)}$.

In summary, the modified van Genuchten model under true triaxial conditions is given by the following equations:

$$
S_{\mathrm{r}}=\frac{w G_{\mathrm{s}}}{e}=\left\{\begin{array}{l}
\left\{1+\left[\left(\frac{e}{1.1943}\right)^{-0.202} s\right]^{-0.252}\right\}^{0.802}, \\
\left\{1+\left[\left(\frac{e}{1.1943}\right)^{-0.202} s\right]^{(-0.0368 b-0.3074)}\right\}^{(0.202 / 0.0368 b+0.3074)}
\end{array}\right.
$$

Therefore, the soil-water characteristic curve adopts the modified van Genuchten model under true triaxial conditions in this paper.

Figure 4 shows a simplified schematic of the unsaturated soil-water characteristic curve. When the suction $s$ is greater than the intake value $s_{\mathrm{e}}$, it is assumed that the main drying curve and the main wetting curve are both straight lines on the $S_{\mathrm{r}}$-lns plane, and the expressions can be written as $[21,22]$

$$
\begin{aligned}
& S_{\mathrm{r}}=S_{\mathrm{r}}^{D}(e)-\lambda_{\mathrm{sr}} \ln s, \\
& S_{\mathrm{r}}=S_{\mathrm{r}}^{w}(e)-\lambda_{\mathrm{sr}} \ln s,
\end{aligned}
$$

where $S_{\mathrm{r}}^{D}(e)$ and $S_{\mathrm{r}}^{w}(e)$ are the degrees of saturation of the main drying curve and the main wetting curve at $s=1 \mathrm{kPa}$, respectively. $\lambda_{\text {sr }}$ are both the slopes of the main drying curve and the main wetting curve.

Assuming that the scan curve is a straight line, the expression is $[21,22]$

$$
S_{\mathrm{r}}=S_{\mathrm{r}}^{s}(e)-\kappa_{\mathrm{s}} \ln s,
$$

where $S_{\mathrm{r}}^{s}(e)$ is the degree of saturation of the scan curve at $s=1 \mathrm{kPa}$ and $\kappa_{\mathrm{s}}$ is the slope of the scan curve. In summary, the degree of saturation increments can be written as follows:

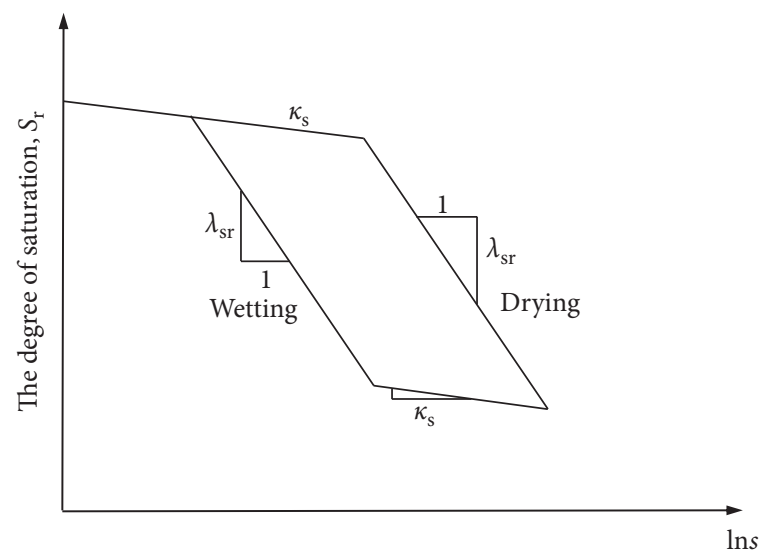

FIGURE 4: A simplified schematic of the unsaturated soil-water characteristic curve.

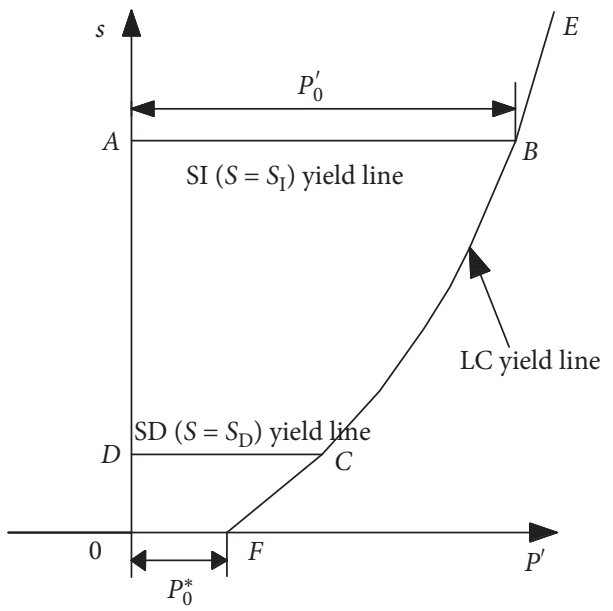

FIGURE 5: SI, SD, and LC yield curves under isotropic stress.

$$
\begin{aligned}
& \mathrm{d} S_{\mathrm{r}}=\left\{1+\left[\left(\frac{e}{a}\right)^{-b_{0}} s\right]^{n}\right\}^{\left(-\left(b_{0}+n / n\right)\right)}\left(\frac{e}{a}\right)^{-b_{0} n} s^{n-1}\left(\frac{b_{0}^{2} s}{e} d e-b_{0} d s\right)-\frac{\lambda_{\mathrm{sr}}}{s} \mathrm{~d} s, \\
& \mathrm{~d} S_{\mathrm{r}}=\left\{1+\left[\left(\frac{e}{a}\right)^{-b_{0}} s\right]^{n}\right\}^{\left(-\left(b_{0}+n / n\right)\right)}\left(\frac{e}{a}\right)^{-b_{0} n} s^{n-1}\left(\frac{b_{0}^{2} s}{e} d e-b_{0} d s\right)-\frac{\kappa_{\mathrm{s}}}{s} \mathrm{~d} s
\end{aligned}
$$

where the soil parameters $a=1.1943$ and $b_{0}=0.202$. Under isotropic consolidation conditions, $n=-0.252$. Under true triaxial shear conditions, $n=-0.0368 b-0.3074$.

Figure 5 shows the yield curves of deformation and degree of saturation under isotropic stress. In addition to the LC yield line, the model adds the SI yield surface (different from the SI yield surface in BBM) and the SD yield surface to describe the elastoplastic process of the hydraulic characteristics of unsaturated soils; the SI yield surface represents the yield surface of the degree of saturation when the suction increases, and the SD yield surface represents the yield surface of the degree of saturation when the suction is reduced. When the suction changes during the drying process $\left(s \geq s_{\mathrm{I}}\right)$ or the humidification process $\left(s \leq s_{\mathrm{D}}\right)$, the degree of saturation increment is calculated according to equation (21) and according to 
equation (22) when the suction is on the SI and SD yield surfaces.

2.4. Constitutive Model under Triaxial Stress. The modified Cambridge model is simple, and the physical meaning of the parameters is clear [6-8]. It is widely used in the study of normal consolidation saturated clay and can reasonably predict the deformation and strength characteristics of normally consolidated saturated clay $[9,10,12,16,19-22]$. In this paper, based on the same form of yield function and plastic potential function of modified Cambridge model, the average soil skeleton stress is used to replace the effective stress of saturated soil.

The yield function of saturated soils is expressed as follows:

$$
f=g=q^{2}+M^{2} p\left(p-p_{0}\right)=0,
$$

where $M$ is the slope of the critical state line on the $p-q$ plane and $p_{0}$ is an isotropic hardening parameter. The slope of critical state line $M$ of unsaturated soils remains unchanged as the suction increase was proposed by Alonso et al. [8], which is the same as that of saturated soil. Therefore, by using the average soil skeleton stress instead of the effective stress of saturated soils, the yield function of unsaturated soils can be obtained as follows:

$$
f=g=q^{2}+M^{2} p^{\prime}\left(p^{\prime}-p_{0}^{\prime}\right)=0 .
$$

That is, the yield function of unsaturated soils can be written as $f=f\left(p^{\prime}, q^{\prime}, p_{0}^{\prime}\right)=0$. Figure 6 shows the yield curves of saturated and unsaturated soils on the $p^{\prime}-q^{\prime}$ plane. Then, the differential form of $f$ in (24) can be expressed as

$$
\mathrm{d} f=\frac{\partial f}{\partial p^{\prime}} \mathrm{d} p^{\prime}+\frac{\partial f}{\partial q^{\prime}} \mathrm{d} p^{\prime}+\frac{\partial f}{\partial p_{0}^{\prime}} \mathrm{d} p_{0}^{\prime}=0 .
$$

The associated flow law is adopted in the average soil skeleton stress space as follows:

$$
d \varepsilon_{i j}^{\mathrm{p}}=\mathrm{d} \lambda \frac{\partial f}{\partial \sigma_{i j}^{\prime}} .
$$

Substituting (9) into (25) gives

$$
\mathrm{d} f=\frac{\partial f}{\partial p^{\prime}} \mathrm{d} p^{\prime}+\frac{\partial f}{\partial p^{\prime}} \mathrm{d} p^{\prime}+\frac{\partial f}{\partial p_{0}^{\prime}} \frac{\partial p_{0}^{\prime}}{\partial p_{0}^{*}} \mathrm{~d} p_{0}^{*}+\frac{\partial f}{\partial p_{0}^{\prime}} \frac{\partial p_{0}^{\prime}}{\partial s} \mathrm{~d} s=0 .
$$

For saturated soil, a similar method to the Cambridge model can be used to obtain the relationship between the isotropic compressive yield stress $p_{0}^{*}$ and the plastic volumetric strain $\varepsilon_{\mathrm{v}}^{\mathrm{p}}$ of saturated soil. The plastic volumetric strain increment $d \varepsilon_{\mathrm{v}}^{\mathrm{p}}$ in saturated soils is caused by the isotropic compressive yield stress increment $\mathrm{d} p_{0}^{*}$ of saturated soils, and in unsaturated soils it is caused by the isotropic compressive yield stress increment $\mathrm{d} p_{0}$ of

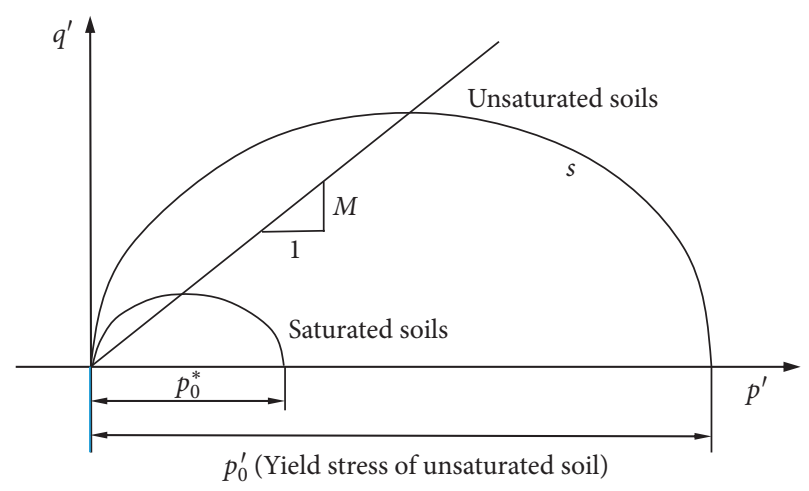

Figure 6: Yield curves on the $p^{\prime}-q^{\prime}$ plane.

unsaturated soils and the suction increment $\mathrm{d} s$. Hence, (5) can be transformed into the following form:

$$
\mathrm{d} p_{0}^{*}=\frac{1+e}{[\lambda(0)-\kappa]} p_{0}^{*} \mathrm{~d} \varepsilon_{\mathrm{v}}^{\mathrm{p}} .
$$

Substituting (26) into (28) gives

$$
\mathrm{d} p_{0}^{*}=\frac{1+e}{[\lambda(0)-\kappa]} p_{0}^{*} \mathrm{~d} \lambda \frac{\partial f}{\partial p^{\prime}} .
$$

Substituting (29) into (27) gives

$\mathrm{d} \lambda=-\frac{\left(\partial f / \partial p^{\prime}\right) \mathrm{d} p^{\prime}+\left(\partial f / \partial q^{\prime}\right) \mathrm{d} q^{\prime}+\left(\partial f / \partial p_{0}^{\prime}\right)\left(\partial p_{0}^{\prime} / \partial s\right) \mathrm{d} s}{\left(\partial f / \partial p_{0}^{\prime}\right)\left(\partial p_{0}^{\prime} / \partial p_{0}^{*}\right)\left(\partial f / \partial p^{\prime}\right)(1+e /(\lambda(0)-\kappa)) p_{0}^{*}}$.

From (24), the following relationships can be obtained:

$$
\frac{\partial f}{\partial p^{\prime}}=2 M^{2} p^{\prime}-M^{2} p_{0}^{\prime}
$$

$\frac{\partial f}{\partial q^{\prime}}=2 q^{\prime}$,

$\frac{\partial f}{\partial p_{0}^{\prime}}=-M^{2} p^{\prime}$,

$\frac{\partial p^{\prime}}{\partial \sigma_{i j}^{\prime}}=\frac{\delta_{i j}}{3}$,

$$
\frac{\partial q^{\prime}}{\partial \sigma_{i j}^{\prime}}=\frac{3\left(\sigma_{i j}^{\prime}-p^{\prime} \delta_{i j}\right)}{2 q^{\prime}},
$$

$\frac{\partial p_{0}^{\prime}}{\partial \sigma_{i j}^{\prime}}=0$.

Therefore, 


$$
\begin{aligned}
\frac{\partial f}{\partial \sigma_{i j}^{\prime}}= & \frac{\partial f}{\partial p^{\prime}} \frac{\partial p^{\prime}}{\partial \sigma_{i j}^{\prime}}+\frac{\partial f}{\partial q^{\prime}} \frac{\partial q^{\prime}}{\partial \sigma_{i j}^{\prime}}+\frac{\partial f}{\partial p_{0}^{\prime}} \frac{\partial p_{0}^{\prime}}{\partial \sigma_{i j}^{\prime}}=\frac{\delta_{i j}}{3} M^{2}\left(2 p^{\prime}-p_{0}^{\prime}\right) \\
& +3\left(\sigma_{i j}^{\prime}-p^{\prime} \delta_{i j}\right), \\
\mathrm{d} \lambda= & \frac{1}{M^{2} p^{\prime} t} \mathrm{~d} p^{\prime}+\frac{2 q^{\prime}}{M^{4} p^{\prime}\left(2 p^{\prime}-p_{0}^{\prime}\right) t} \mathrm{~d} q^{\prime}+\frac{\left(\partial p_{0}^{\prime} / \partial s\right)}{M^{2}\left(p_{0}^{\prime}-2 q^{\prime}\right) t} \mathrm{~d} s
\end{aligned}
$$

Substituting (37) and (38) into (26), the plastic strain increment form can be written as follows:

$$
\begin{aligned}
\mathrm{d} \varepsilon_{i j}^{\mathrm{p}}= & \frac{\left(2 M^{2} p^{\prime}-M^{2} p_{0}^{\prime}+6 q^{\prime}\right)}{3 M^{2} t}\left[\frac{1}{p^{\prime}} \mathrm{d} p^{\prime}+\frac{2 q^{\prime}}{M^{2} p^{\prime}\left(2 p^{\prime}-p_{0}^{\prime}\right)} \mathrm{d} q^{\prime}\right. \\
& \left.+\frac{\left(\partial p_{0}^{\prime} / \partial s\right)}{\left(p_{0}^{\prime}-2 p^{\prime}\right)} \mathrm{d} s\right]
\end{aligned}
$$

where

$$
\begin{aligned}
& t=p_{0}^{*} \frac{1+e}{\kappa-\lambda(0)} \frac{\partial p_{0}^{\prime}}{\partial p_{0}^{*}}=p_{0}^{*} \frac{1+e}{\kappa-\lambda(0)} \frac{\lambda(0)-\kappa}{\lambda(s)-\kappa}\left(\frac{p_{0}^{*}}{p_{\mathrm{c}}^{\prime}}\right)^{((\lambda(0)-\lambda(s)) /(\lambda(s)-\kappa))} \\
& \frac{\partial p_{0}^{\prime}}{\partial s}=\frac{\lambda_{\mathrm{s}} p_{\mathrm{a}} p_{0}^{\prime}[\lambda(0)-\kappa]}{\left(p_{\mathrm{a}}+s\right)^{2}[\lambda(s)-\kappa]^{2}} \ln \frac{p_{\mathrm{c}}^{\prime}}{p_{0}^{*}}
\end{aligned}
$$

According to generalized Hook's law, the elastic strain increment can be written as follows:

$$
\mathrm{d} \varepsilon_{i j}^{\mathrm{e}}=\frac{1+\mu}{E} \mathrm{~d} \sigma_{i j}-\frac{\mu}{E} \mathrm{~d} \sigma_{k k} \delta_{i j}
$$

Then,

$$
\mathrm{d} \varepsilon_{\mathrm{v}}^{\mathrm{e}}=\frac{3(1-2 \mu)}{E} \mathrm{~d} p^{\prime} .
$$

Assume Poisson's ratio $\mu=1 / 3$; the expression of elastic modulus can be obtained by combining (7)

$$
E=3(1-2 \mu) \frac{1+e}{\kappa} p^{\prime}=\frac{1+e}{\kappa} p^{\prime} .
$$

Therefore, in this model, the plastic strain increment caused by an increase in the average soil skeleton stress or a decrease in the suction can be calculated by (39); the elastic strain increment can be calculated by (42), and the increment of degree of saturation can be calculated by (21) and (22). The model is based on the elastoplastic theory; the deformation is divided into elastic strain and plastic strain; the elastic strain is processed in the unloading and reloading curves based on the generalized Hooke's law, and the plastic strain is processed in the original loading curve. The model requires seven basic parameters of soils, i.e., $\lambda(0), \kappa, \lambda_{\mathrm{s}}, p_{\mathrm{c}}^{\prime}, M$, $\lambda_{\mathrm{sr}}$, and $\kappa_{\mathrm{s}}$. The model can predict the mechanical properties of unsaturated soils under isotropic and triaxial stresses conditions and can reflect the influence of degree of saturation on soil elastoplasticity. However, the stress state of geomaterials is usually in three-dimensional conditions, so it would be very meaningful to generalize the model to the three-dimensional stress state.

2.5. Transform Stress Three-Dimensional Method. Using the SMP criterion-based transform stress method proposed by Yao et al. [25-27], firstly, the stress $\sigma_{i j}^{\prime}$ in the general stress space is transformed into the stress $\tilde{\sigma}_{i j}$ in the transformed stress space, so that the yield surface changes from an irregular curved triangle to a Mises circle; then, it transforms the stress space and introduces the transformed stress $\widetilde{\sigma}_{i j}$ into the existing model for calculation to reflect the real and complex three-dimensional stress-strain relationship. As shown in Figure 7, the SMP criterion is a closed convex curve shown by a solid line on the $\pi$ plane of the general space, and the SMP criterion is a circle indicated by a broken line on the $\pi$ plane of the transformed stress space; the radius is $r_{0}^{\prime}$. Also,

$$
\begin{aligned}
& r_{0}^{\prime}=\sqrt{\frac{2}{3}} q_{\mathrm{c}}^{\prime}=\sqrt{\frac{2}{3}} \frac{2 I_{1}^{\prime}}{3 \sqrt{\left(I_{1}^{\prime} I_{2}^{\prime}-I_{3}^{\prime}\right) /\left(I_{1}^{\prime} I_{2}^{\prime}-9 I_{3}^{\prime}\right)}-1}, \\
& q_{\mathrm{c}}^{\prime}=\sqrt{\frac{3}{2}} r_{0}^{\prime}=\frac{2 I_{1}^{\prime}}{3 \sqrt{\left(I_{1}^{\prime} I_{2}^{\prime}-I_{3}^{\prime}\right) /\left(I_{1}^{\prime} I_{2}^{\prime}-9 I_{3}^{\prime}\right)}-1}
\end{aligned}
$$

where

$$
\left\{\begin{array}{l}
I_{1}^{\prime}=\sigma_{1}^{\prime}+\sigma_{2}^{\prime}+\sigma_{3}^{\prime}, \\
I_{2}^{\prime}=\sigma_{1}^{\prime} \sigma_{2}^{\prime}+\sigma_{2}^{\prime} \sigma_{3}^{\prime}+\sigma_{3}^{\prime} \sigma_{1}^{\prime}, \\
I_{3}^{\prime}=\sigma_{1}^{\prime} \sigma_{2}^{\prime} \sigma_{3}^{\prime} .
\end{array}\right.
$$

As shown in Figure 7, assuming that the stress $\sigma_{i}^{\prime}$ space coordinate axis is coaxial with the stress $\widetilde{\sigma}_{i}$ space coordinate axis on the $\pi$ plane, the point $\mathrm{A}(\tilde{p} \tilde{q} \tilde{\theta})$ and the point $\mathrm{A}^{\prime}\left(p^{\prime}, q^{\prime}, \theta^{\prime}\right)$ satisfy the following relationship:

$$
\begin{aligned}
& \widetilde{p}=p^{\prime}, \\
& \widetilde{q}=q_{c}^{\prime}, \\
& \widetilde{\theta}=\theta,
\end{aligned}
$$

The transformed stress tensor is obtained from equation (46):

$$
\tilde{\sigma}_{i j}=p^{\prime} \delta_{i j}+\frac{q_{\mathrm{c}}^{\prime}}{q^{\prime}}\left(\sigma_{i j}^{\prime}-p^{\prime} \delta_{i j}\right) .
$$

In the transformed stress space, the yield function of unsaturated soils can be written as follows:

$$
\begin{aligned}
\tilde{f} & =\widetilde{q}+M^{2} \widetilde{p}\left(\widetilde{p}-\widetilde{p}_{0}\right)=0, \\
\mathrm{~d} \varepsilon_{i j}^{\mathrm{p}} & =\mathrm{d} \widetilde{\lambda} \frac{\partial \widetilde{f}}{\partial \widetilde{\sigma}_{i j}} .
\end{aligned}
$$




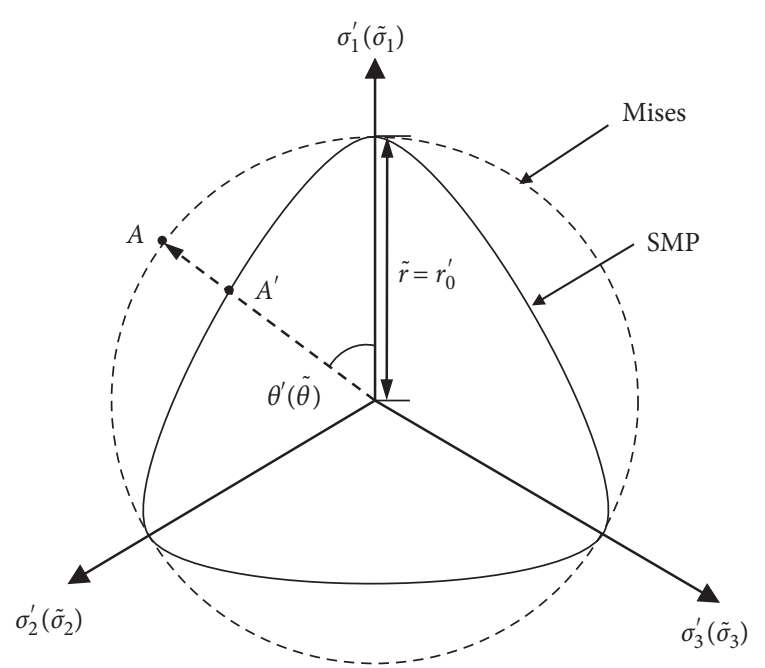

Figure 7: Transform stress method based on SMP criterion.

The incremental form of plastic strain can be written as follows:

$$
\begin{aligned}
\mathrm{d} \varepsilon_{i j}^{\mathrm{p}}= & \frac{\left(2 M^{2} \widetilde{p}-M^{2} \widetilde{p}_{0}+6 \widetilde{q}\right)}{3 M^{2} \widetilde{t}}\left[\frac{1}{\widetilde{p}} \mathrm{~d} \widetilde{p}+\frac{2 \widetilde{q}}{M^{2} \widetilde{p}\left(2 \widetilde{p}-\widetilde{p}_{0}\right)} \mathrm{d} \widetilde{q}\right. \\
& \left.+\frac{\left(\partial \widetilde{p}_{0} / \partial s\right)}{\left(\widetilde{p}_{0}-2 \widetilde{p}\right)} \mathrm{d} s\right],
\end{aligned}
$$

where

$$
\begin{aligned}
\tilde{t} & =\widetilde{p}_{0}^{*} \frac{1+e}{\kappa-\lambda(0)} \frac{\lambda(0)-\kappa}{\lambda(0)-\kappa}\left(\frac{\widetilde{p}_{0}^{*}}{\widetilde{p}_{\mathrm{c}}}\right)^{(\lambda(0)-\lambda(s) / \lambda(s)-\kappa),}, \\
\frac{\partial \widetilde{p}_{0}}{\partial s} & =\frac{\lambda_{\mathrm{s}} p_{\mathrm{a}} \widetilde{p}_{0}[\lambda(0)-\kappa]}{\left(p_{\mathrm{a}}+s\right)^{2}[\lambda(s)-\kappa]^{2}} \ln \frac{\widetilde{p}_{\mathrm{c}}}{\widetilde{p}_{0}^{*}} .
\end{aligned}
$$

2.6. Experimental Validation. A modified unsaturated true triaxial apparatus was used to conduct a series of controlling net average stress and intermediate principal stress parameter tests under measuring suction conditions to verify the applicability of the developed model. The loess was taken from Xi'an, Shaanxi, China. High-quality intact block samples $(25 \mathrm{~cm} \times 25 \mathrm{~cm} \times 30 \mathrm{~cm}$ in size $)$ were collected at a depth of $8 \mathrm{~m}$ from an excavated pit. The in situ gravimetric water content of the intact loess is $15.6 \%$, the dry density is $1.35 \mathrm{~g} / \mathrm{cm}^{3}$, and the specific gravity is 2.7 . The initial void ratio is 1.007 . The plastic limit and liquid limit are $20.91 \%$ and $31.67 \%$, respectively. The clay $(<0.002 \mathrm{~mm})$ and silt $(0.002-0.063 \mathrm{~mm})$ fractions of the test loess are $28.2 \%$ and $72.1 \%$. According to ASTM (2006) D2487, the test loess is classified as clay of low plasticity. The preparation of an intact specimen involved first cutting a small soil block of specified size $(7 \mathrm{~cm} \times 7 \mathrm{~cm} \times 14 \mathrm{~cm})$ from the block sample. The test is a constant water content test, which consists of measuring the initial suction, isotropic net stress compression test, and shear test of equal $b$ value. First, under the condition of no stress, the initial suction $s_{0}=170 \mathrm{kPa}$ of the sample was measured by the axis translation technology, and then the sample was stage-loaded to $300 \mathrm{kPa}$; the applied load of each stage was $25 \mathrm{kPa}$; then it was unloaded and rebounded to $50 \mathrm{kPa}$ and then subjected to a shear test of equal $p(p=400 \mathrm{kPa})$ and equal $b$ value $(b=0,0.15,0.5$, 0.7 , and 1). The shear rate of the shear test is $0.005 \mathrm{~mm} / \mathrm{min}$, and the test ends when the axial strain reaches $12 \%$. During the whole test process, the test is controlled to exhaust without drainage; that is, the applied air pressure remains unchanged, the pore water pressure is tested, and the change in suction of the sample is tested using the axis translation technology. The compression stability criterion is that the external volume change of the sample is less than $0.003 \mathrm{~cm}^{3} / \mathrm{h}$ and the pore water pressure change is less than $0.5 \mathrm{kPa} / \mathrm{h}$. According to the test results, the model parameter values were obtained as follows: $\lambda(0)=0.106$, $\lambda_{\mathrm{s}}=0.109, \kappa=0.007, M=0.988, p_{\mathrm{c}}^{\prime}=60 \mathrm{kPa}, \lambda_{\mathrm{sr}}=0.087$, and $\kappa_{\mathrm{s}}=0.0116$. The determination methods of the model parameters are as follows [8]: (1) $\lambda(0)$ and $\lambda(s)$ are determined by the slope of the normal compression curve of $v$ - $\ln p^{\prime}$ for saturated and unsaturated soils, respectively, and $\lambda_{\mathrm{s}}$ is determined by equation (8). (2) $\kappa$ is determined by the slope of the unloading curve of $v$ - $\ln p^{\prime}$ for unsaturated soils. (3) $M$ is determined by the slope of the critical state line of $p^{\prime}-q^{\prime}$ plane. (4) According to the saturated soil drying test and dry soil humidification test, the relationship between the matric suction and the degree of saturation can be measured to determine $\lambda_{\mathrm{s}}$ and $\kappa_{\mathrm{s}}$. (5) $p_{\mathrm{c}}^{\prime}$ is isotropic stress that does not make wetting deformation when suction is reduced and which is determined by the relevant relational equations on the $v$ - $\ln p^{\prime}$ plane. The obtained test data $(O$ marks) and predictions (solid curves) are shown in Figure 8. For the convenience of drawing, the volumetric strain is increased by one unit in the diagram, so the actual volumetric strain should decrease one unit. It can be seen from Figures 8(a)-8(e) that, in the equal $b$ and equal $p$ tests, as the $b$ value increases, (i) the net large principal stress increases and the large principal stress direction strain $\varepsilon_{1}$ is in the shearing contraction state. (ii) The net intermediate principal stress changes from a decreasing state to an increasing state, and the intermediate principal stress direction strain $\varepsilon_{2}$ gradually develops from dilatancy to shearing contraction. (iii) The net small principal stress is always in a reduced state, so the small principal stress direction strain $\varepsilon_{3}$ is always in the dilating state, and the volumetric strain $\varepsilon_{\mathrm{v}}$ changes from the dilatancy to shearing contraction. Figure 8(f) shows the variation curve of the degree of saturation in the isotropic net stress compression tests. It can be seen from Figure 8 (f) that the degree of saturation increases with an increase in net mean stress. Figure $8(\mathrm{~g})$ shows the variation curves of the degree of saturation during shearing at different $b$-values. It can be seen from Figure $8(\mathrm{~g})$ that the degree of saturation of soils increases with the development of shear deformation under different $b$-values; the principal stress ratio increases as the $b$ value increases, and as the principal stress ratio increases, the difference in degree of saturation at different $b$-value becomes larger. The comparisons demonstrate that the 


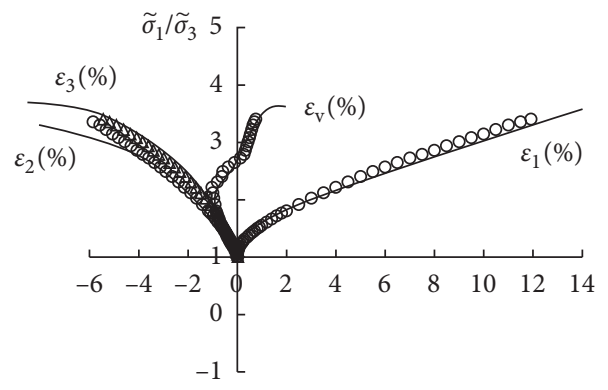

- Prediction
- Test data

(a)

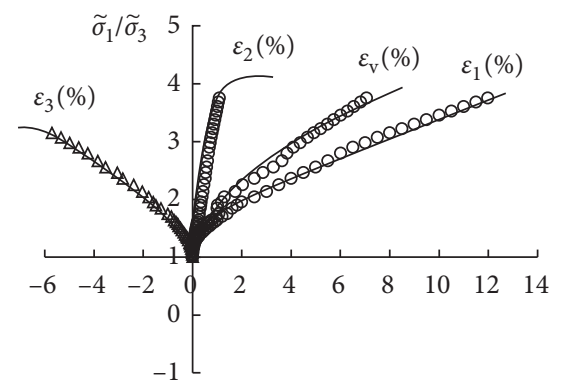

— Prediction

- Test data

(c)

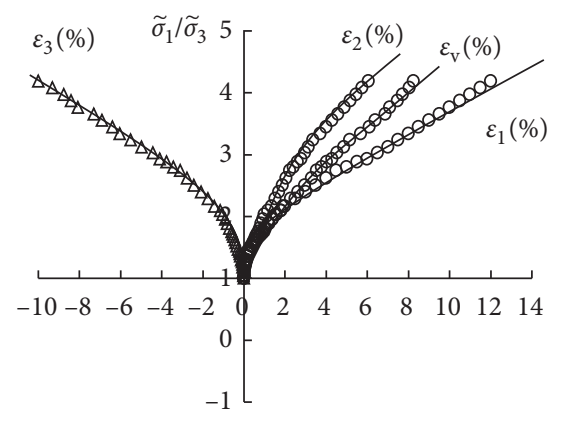

Prediction

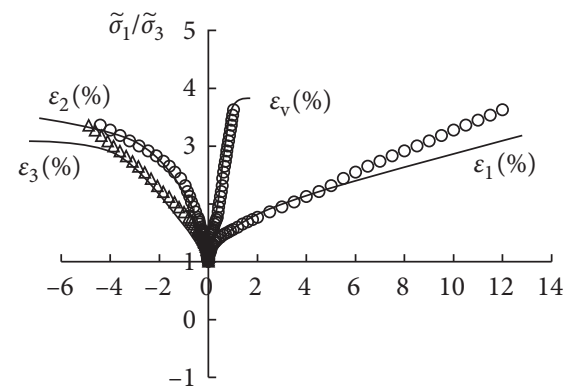

- Prediction

- Test data

(b)

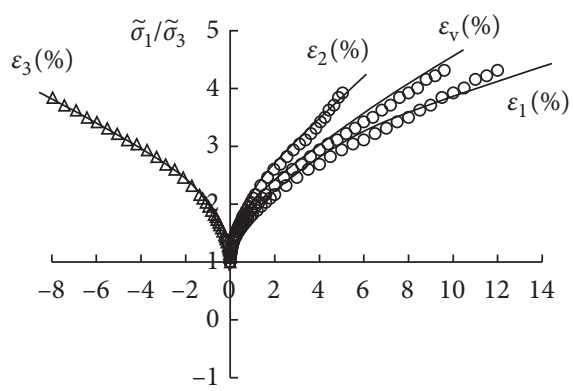

- Prediction

- Test data

(d)

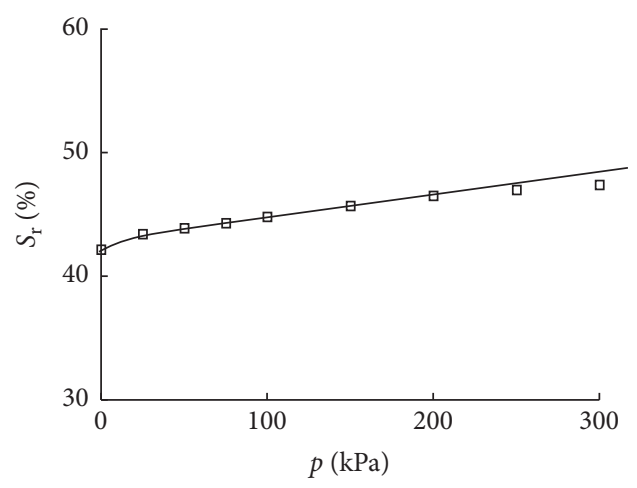

口 $\mathrm{p}-\mathrm{Sr}$

(e)

(f)

FIgURE 8: Continued. 


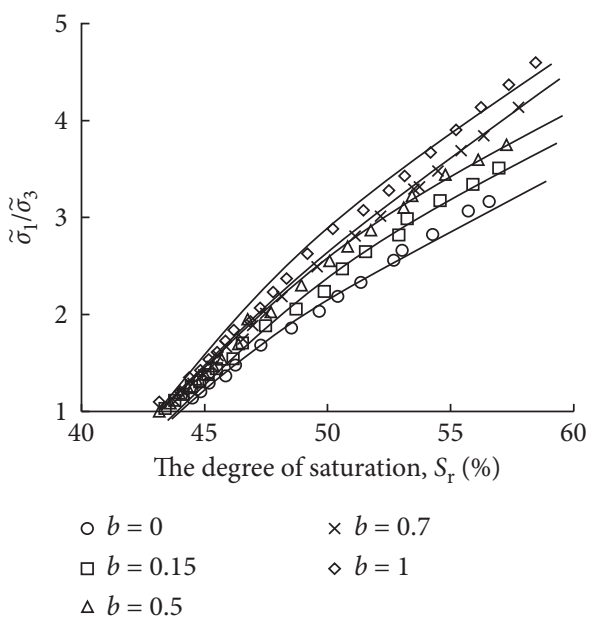

(g)

Figure 8: Comparison between true-triaxial tests and model predictions. (a) $b=0$, (b) $b=0.15$, (c) $b=0.5$, (d) $b=0.7$, and (e) $b=1.0$. (f) Variation of the degree of saturation in the isotropic net stress compression tests. (g) Variation of the degree of saturation at different $b$ values.

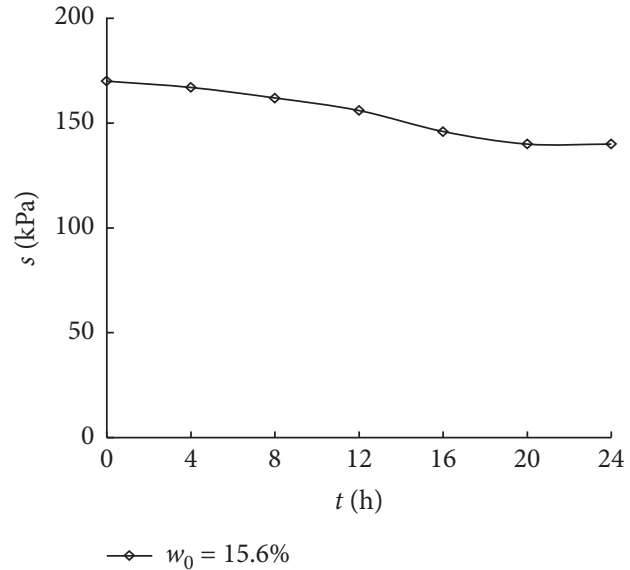

(a)

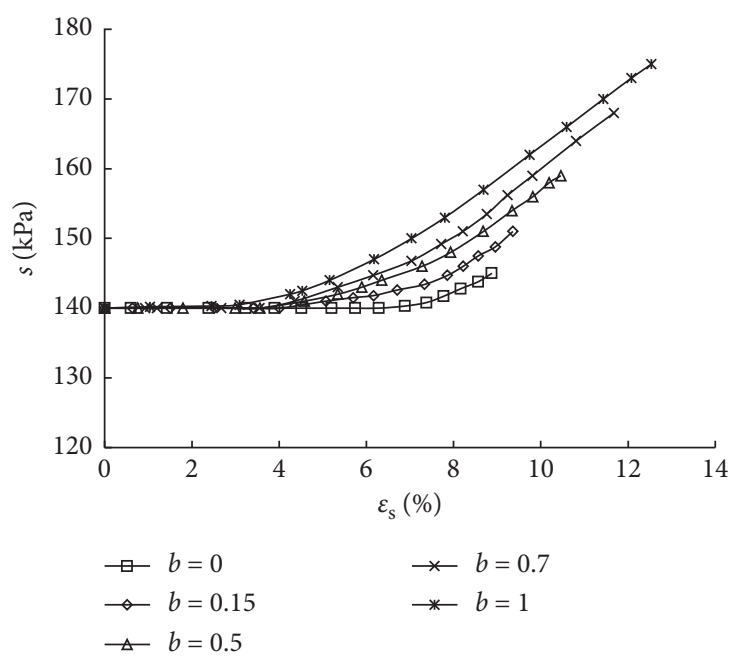

(b)

Figure 9: Variation characteristics of suction in true triaxial tests. (a) Changes in suction during isotropic compression. (b) Changes in suction during shearing.

established model can reasonably reflect the strength properties and the degree of saturation of unsaturated soils under true triaxial conditions.

(Note: $\varepsilon_{1}$ is the large principal stress direction strain; $\varepsilon_{2}$ is the intermediate principal stress direction strain; $\varepsilon_{3}$ is the small principal stress direction strain; $\varepsilon_{\mathrm{v}}$ is the volumetric strain; $\left(\widetilde{\sigma_{1}} / \tilde{\sigma_{3}}\right)$ is the ratio of net large principal stress to net minor principal stress.)

When the isotropic net stress is equal to $300 \mathrm{kPa}$, Figure 9(a) shows the changes in suction during isotropic compression. It can be seen from Figure 9(a) that, under the effect of isotropic net compressive stress, the suction decreases with time, and the suction basically reaches a stable state after 20 hours. This is because, under the condition of constant water content, the water content remains unchanged, the soil volume shrinks under the effect of isotropic net compressive stress, the porosity ratio decreases, the saturation increases, and the suction decreases accordingly. Figure 9(b) shows the changes in suction during shearing at different $b$ values. It can be seen from Figure 9(b) that, in the equal $b$ and equal $p$ tests, (i) the $s-\varepsilon_{\mathrm{s}}$ relationship curves all show a slight decrease or remain the same and then show a rapid increase. It is shown that the suction of the soil at the beginning of shearing is slightly reduced or unchanged compared with that after the isotropic consolidation is completed. Then, the suction increases faster during the shearing process. (ii) As the $b$ value increases, the $s-\varepsilon_{s}$ relationship curve shows an upward trend; that is, when the 
value of $\varepsilon_{\mathrm{s}}$ is constant, the suction increases with an increase in $b$ value, indicating that the intermediate principal stress has a certain effect on the suction of intact loess. (iii) When $b$ value is large, the ascending section of suction increases faster.

\section{Conclusions}

A new constitutive model for unsaturated soils using the degree of saturation and effective stress is proposed in this paper. Applying the modified Cambridge model as a generalization, the degree of saturation is introduced into the elastoplastic model of unsaturated soil. Under the condition of ensuring that the model parameters are unchanged, the model is transformed into three dimensions based on the SMP criterion transformation stress method. The soil-water characteristic curves of unsaturated intact loess under unstressed, isotropic compression and shear conditions were measured by a series of isotropic consolidation and shear tests under undrained conditions using unsaturated true triaxial tests. Enhanced modified van Genuchten model under true triaxial conditions is also proposed in this paper to describe hydromechanical behaviours of unsaturated soils. The proposed constitutive model can capture the observed mechanical and hydraulic behaviours. Then, the capacity of the proposed model was verified via equal $p$ and equal $b$ value true triaxial tests conducted by the authors.

\section{Data Availability}

The data used to support the findings of this study are available from the corresponding author upon request.

\section{Conflicts of Interest}

The authors declare that they have no conflicts of interest.

\section{Acknowledgments}

The authors would like to acknowledge the National Natural Science Foundation of China ((51808197), the Doctorate Fund of Henan Polytechnic University (B2018-64) and the Key Research Project of Colleges and Universities in Henan Province (19A560010) which collectively funded this project.

\section{References}

[1] A. W. Bishop, "The principle of effective stress," Teknisk Ukeblad, vol. 106, no. 39, pp. 859-863, 1959.

[2] J. D. Coleman, "Correspondence," Géotechnique, vol. 12, no. 4 , pp. $348-350,1962$.

[3] G. E. Blight, "A study of effective stresses for volume change, in moisture equilibrium and moisture change in soils beneath covered areas," in Proceedings of a Conference in Symposium, G. D. Aitchisom and E. D Sydney, Eds., pp. 259-269, Canberra, Australia, June 1965.

[4] J. E. B. Jennings and J. B. Burland, "Limitations to the use of effective stresses in partly saturated soils," Géotechnique, vol. 12, no. 2, pp. 125-144, 1962.
[5] D. G. Fredlund, N. R. Morgenstern, and R. A. Widger, "The shear strength of unsaturated soils," Canadian Geotechnical Journal, vol. 15, no. 3, pp. 313-321, 1978.

[6] D. G. Fredlund and N. R. Morgenstern, "Constitutive relations for volume change in unsaturated soils," Canadian Geotechnical Journal, vol. 13, no. 3, pp. 261-276, 1976.

[7] A. Gens, E. E. Alonso, and A. Josa, "Elasto-plastic modeling of partially saturated soils," in Proceedings of a Numerical Models Conference in Geomechanics III, pp. 163-170, Elsevier, London, UK, 1989.

[8] E. E. Alonso, A. Gens, and A. Josa, "A constitutive model for partially saturated soils," Géotechnique, vol. 40, no. 3, pp. 405-430, 1990.

[9] Y. Kohgo, M. Nakano, and T. Miyazaki, "Theoretical aspects of constitutive modelling for unsaturated soils," Soils and Foundations, vol. 33, no. 4, pp. 49-63, 1993.

[10] S. J. Wheeler and V. Sivakumar, "An elasto-plastic critical state framework for unsaturated soil," Géotechnique, vol. 45, no. 1, pp. 35-53, 1995.

[11] Y. J. Cui and P. Delage, "Yielding and plastic behaviour of an unsaturated compacted silt," Géotechnique, vol. 46, no. 2, pp. 291-311, 1996.

[12] K. Georgiadis, D. M. Potts, and L. Zdravkovic, "Three-dimensional constitutive model for partially and fully saturated soils," International Journal of Geomechanics, vol. 5, no. 3, pp. 244-255, 2005.

[13] P. J. Shamsabadi, "Numerical and Physical Modeling of Cone Penetration in Unsaturated Soils and Numerical Simulation of Fracture Propagation in Shale Rock during Brazilian Test," University of New Hampshire, Durham, NH, USA, 2017.

[14] P. Jarast and M. Ghayoomi, "Simple numerical model to simulate penetration testing in unsaturated soils," E3S Web of Conferences, vol. 9, 2016.

[15] M. Ghayoomi, G. Suprunenko, and M. Mirshekari, "Cyclic triaxial test to measure strain-dependent shear modulus of unsaturated sand," International Journal of Geomechanics, vol. 17, no. 9, 2017.

[16] G. Bolzon, B. A. Schrefler, and O. C. Zienkiewicz, "Elastoplastic soil constitutive laws generalized to partially saturated states," Géotechnique, vol. 46, no. 2, pp. 279-289, 1996.

[17] N. Khalili and M. H. Khabbaz, "A unique relationship for $\chi$ for the determination of the shear strength of unsaturated soils," Geotechnique, vol. 48, no. 2, pp. 681-687, 1998.

[18] N. Khalili, F. Geiser, and G. E. Blight, "Effective stress in unsaturated soils: review with new evidenceffective stress in unsaturated soils: review with new evidence," International Journal of Geomechanics, vol. 4, no. 2, pp. 115-126, 2004.

[19] B. Loret and N. Khalili, "An effective stress elastic-plastic model for unsaturated porous mediaffective stress elasticplastic model for unsaturated porous media," Mechanics of Materials, vol. 34, no. 2, pp. 97-116, 2002.

[20] D. Sheng, S. W. Sloan, and A. Gens, "A constitutive model for unsaturated soils: thermomechanical and computational aspects," Computational Mechanics, vol. 33, no. 6, pp. 453-465, 2004.

[21] D. A. Sun, D. C. Sheng, H. B. Cui, and S. W. Sloan, "A densitydependent elastoplastic hydro-mechanical model for unsaturated compacted soils," International Journal for Numerical and Analytical Methods in Geomechanics, vol. 31, no. 11, pp. 1257-1279, 2007.

[22] D. A. Sun, D. Sheng, and S. W. Sloan, "Elastoplastic modelling of hydraulic and stress-strain behaviour of unsaturated soils," Mechanics of Materials, vol. 39, no. 3, pp. 212-221, 2007. 
[23] J. M. Pereira, H. Wong, P. Dubujet, and P. Dangla, “Adaptation of existing behaviour models to unsaturated states: application to CJS model," Int J Numer Anal Meth Geomech, vol. 29, no. 15, pp. 1127-1155, 2005.

[24] C. P. Wroth and G. T. Houlsby, "Soil mechanics-property characterization and analysis procedures," in Proceedings of the 11th International Conference on Soil Mechanics and Foundation Engineering, vol. 1, ISSMFE, San Francisco, CA, USA, pp. 1-55, August 1985.

[25] Y.-P. Yao and D. A. Sun, "Application of lade's criterion to cam-clay model," Journal of Engineering Mechanics, vol. 126, no. 1, pp. 112-119, 2000.

[26] Y.-P. Yao, A.-N. Zhou, and D.-C. Lu, "Extended transformed stress space for geomaterials and its application," Journal of Engineering Mechanics, vol. 133, no. 10, pp. 1115-1123, 2007.

[27] Y.-P. Yao, W. Hou, and A.-N. Zhou, "UH model: three-dimensional unified hardening model for overconsolidated claysfied hardening model for over consolidated clays," Géotechnique, vol. 59, no. 5, pp. 451-469, 2009.

[28] O. C. Zienkiewicz and G. N. Pande, "Some useful forms of isotropic yield surface for soil and rock mechanics," in Finite Elements in Geomechanics, G. Gudehus, Ed., pp. 179-190, Wiley, London, UK, 1977.

[29] M. F. Randolph, "Generalising the cam-clay models," in Symposium on the Implementation of Critical State Soil Mechanics, pp. 1-5, Cambridge University, Cambridge, U.K., 1982.

[30] P. V. Lade, "Stress-strain theory for normally consolidated clay," in Proceedings of the 3rd International Conference Numerical Methods in Geomechanics, pp. 1352-1337, Aachen, Germany, 1979.

[31] H. Matsuoka, Y.-P. Yao, and D. A. Sun, "The Cam-clay models revised by the SMP criterion," Soils and Foundations, vol. 39, no. 1, pp. 81-95, 1999.

[32] K. Hashiguchi, K. Saitoh, T. Okayasu, and S. Tsutsumi, "Evaluation of typical conventional and unconventional plasticity models for prediction of softening behaviour of soils," Géotechnique, vol. 52, no. 8, pp. 561-578, 2002.

[33] M. Rouainia and D. Muir Wood, "A kinematic hardening constitutive model for natural clays with loss of structure," Géotechnique, vol. 50, no. 2, pp. 153-164, 2000.

[34] A.-N. Zhou, "A contact angle-dependent hysteresis model for soil-water retention behaviour," Computers and Geotechnics, vol. 49, pp. 36-42, 2013.

[35] A. Zhou, S. Wu, J. Li, and D. Sheng, "Including degree of capillary saturation into constitutive modelling of unsaturated soils," Computers and Geotechnics, vol. 95, pp. 82-98, 2018.

[36] R. Tamagnini, "An extended Cam-Clay model for unsaturated soils with hydraulic hysteresis," Géotechnique, vol. 54, no. 3, pp. 223-228, 2004.

[37] N. Khalili and S. Zargarbashi, "Influence of hydraulic hysteresis on effective stress in unsaturated soilsfluence of hydraulic hysteresis on effective stress in unsaturated soils," Géotechnique, vol. 60, no. 9, pp. 729-734, 2010.

[38] S. J. Wheeler, R. S. Sharma, and M. S. R. Buisson, "Coupling of hydraulic hysteresis and stress-strain behaviour in unsaturated soils," Géotechnique, vol. 53, no. 1, pp. 41-54, 2003.

[39] D. Gallipoli, A. Gens, G. Chen, and F. D’Onza, "Modelling unsaturated soil behaviour during normal consolidation and at critical state," Computers and Geotechnics, vol. 35, no. 6, pp. 825-834, 2008.

[40] G. T. Houlsby, "The work input to an unsaturated granular material," Géotechnique, vol. 47, no. 1, pp. 193-196, 1997.
[41] D.-c. Lu, X.-q. Li, X.-l. Du, and J.-y. Liang, "A simple 3D elastoplastic constitutive model for soils based on the characteristic stress," Computers and Geotechnics, vol. 109, pp. 229-247, 2019.

[42] H. Ghasemzadeh, M. H. Sojoudi, S. A. Ghoreishian Amiri, and M. H. Karami, "Elastoplastic model for hydro-mechanical behavior of unsaturated soils," Soils and Foundations, vol. 57, no. 3, pp. 371-383, 2017.

[43] D. G. Fredlund and A. Xing, "Equations for the soil-water characteristic curve," Canadian Geotechnical Journal, vol. 31, no. 4, pp. 521-532, 1994.

[44] W. S. Sillers, D. G. Fredlund, and N. Zakerzaheh, "Mathematical attributes of some soil-water characteristic curve models," Geotechnical and Geological Engineering, vol. 19, no. 3-4, pp. 243-283, 2001.

[45] R. H. Brooks and A. T. Corey, "Hydraulic properties of porous media," Colorado State University Hydrology Paper, vol. 27, no. 3, pp. 22-27, 1964.

[46] M. T. Van Genuchten, "A closed-form equation for predicting the hydraulic conductivity of unsaturated soils," Soil Science Society of America Journal, vol. 4, no. 5, pp. 92-898, 1980.

[47] E. C. Leong and H. Rahardjo, "Review of soil-water characteristic curve equations," Journal of Geotechnical and Geoenvironmental Engineering, vol. 123, no. 12, 1997.

[48] C. W. Ng and Y. W. Pang, "Experimental investigations of the soil-water characteristics of a volcanic soil," Canadian Geotechnical Journal, vol. 37, no. 6, pp. 1252-1264, 2000.

[49] C. W. W. Ng, H. Sadeghi, S. K. B. Hossen, C. F. Chiu, E. E. Alonso, and S. Baghbanrezvan, "Water retention and volumetric characteristics of intact and re-compacted loess," Canadian Geotechnical Journal, vol. 53, no. 8, pp. 1258-1269, 2016.

[50] T. M. Thu, H. Rahardjo, and E.-C. Leong, "Soil-water characteristic curve and consolidation behavior for a compacted silt," Canadian Geotechnical Journal, vol. 44, no. 3, pp. 266275, 2007.

[51] J. J. Fang, Y. X. Feng, and S. J. Shao, "Soil-water characteristics of intact loess Q3 under true triaxial condition," Rock and Soil Mechanics, vol. 38, no. 9, pp. 1001-1009, 2017, in Chinese.

[52] A. Tarantino, "A water retention model for deformable soils," Géotechnique, vol. 59, no. 9, pp. 751-762, 2009. 